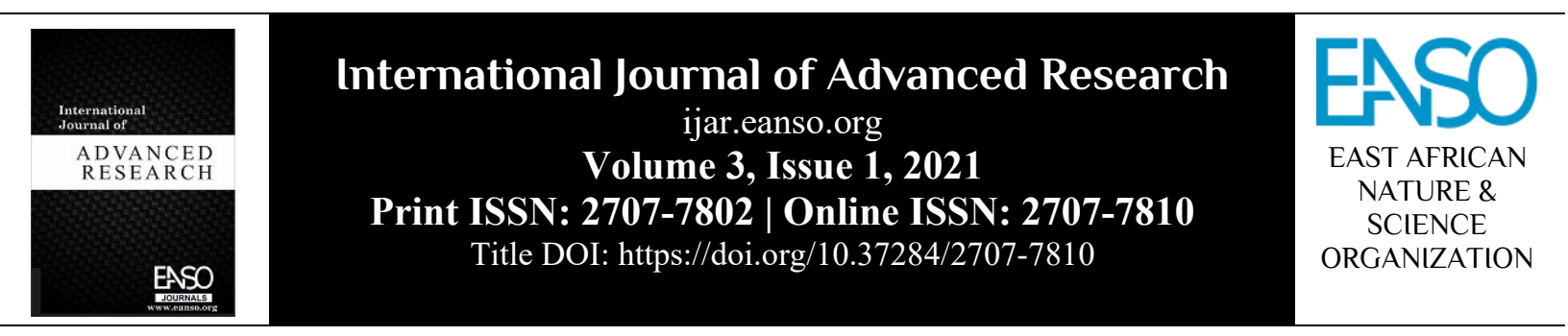

Original Article

\title{
'Drawing with My Students' - The Role of Surrealism in Self-Expression among University Art Students. Analysis of Selected Surrealistic Work by Fourth Year Students at Kenyatta University
}

\author{
Dr. Kamau Wango, $P h D^{l *}$ \\ 1 Department of Fine Art and Design, Kenyatta University, P. O. Box 43844 - 00100, Nairobi, Kenya; ORCID: \\ https://orcid.org/0000-0002-0185-1355. \\ * Author for Correspondence email: kamauwango@gmail.com.
}

Article DOI: https://doi.org/10.37284/ijar.3.1.272

\section{Publication Date: ABSTRACT}

17 February 2021 Surrealistic art is one of the most engaging and intriguing art genres.

Keywords:

Surrealism,

Dream-Like,

Dreams,

Unconscious,

Bizarre,

Irrational.

Surrealism itself is considered to have been the most influential art movement of the $20^{\text {th }}$ century. Started in the 1920 s as a literary movement that eventually took on a visual dimension, its foundational principles have continued to influence the thought process and style of many modern artists in the realm of self-expression. In their studies of many disciplines in the art including genres of painting, drawing and sculpture, students of art at the University usually find the concept of surrealism initially difficult to decipher mainly because of the uniqueness of its own description. The dream-like imageries of surrealism are derived from dreams and the unconscious mind; hence, the students have to contend with the derivation of subject matter from an unusual source. This is challenging for most of them since they are used to formulating subject matter from a purely academic perspective and from themes that they ordinarily relate to in their environment or can easily reference. Although students embark on drawing from their first year of study, they are introduced to surrealistic drawing as a unit in their final year. With their drawing background, it is presumed that by their final year, they have attained adequate levels of drawing skills for application in any artistic challenge. This study examines, through analysis of selected works, firstly, the extent to which students are able to internalise the concept of surrealism and apply it in the construction of the artistic composition, and secondly whether their drawings demonstrate an individual capacity for selfexpression and the derivation of meaning, through dream-like imageries drawn from the unconscious mind. The students were exposed to preliminary studies and examination of surrealistic work, discussions of subject matter, origination, style and technique in the course of their unit programme. For the purpose of uniformity of medium, they were instructed to work only in 
pencil. They were subsequently accorded adequate time and space to embark on their work with class presentations and discussions at prescribed intervals. The resultant drawings were many and varied and the ones selected are those that displayed good artistic execution and/or displayed a certain profoundness of meaning or interpretation.

\section{APA CITATION}

Wango, K. (2021). 'Drawing with My Students' - The Role of Surrealism in Self-Expression among University Art Students. Analysis of Selected Surrealistic Work by Fourth Year Students at Kenyatta University. International Journal of Advanced Research, 3(1), 1-19. https://doi.org/10.37284/ijar.3.1.272

\section{CHICAGO CITATION}

Wango, Kamau. 2021. “Drawing with My Students' - The Role of Surrealism in Self-Expression among University Art Students. Analysis of Selected Surrealistic Work by Fourth Year Students at Kenyatta University”. International Journal of Advanced Research 3 (1), 1-19. https://doi.org/10.37284/ijar.3.1.272.

\section{HARVARD CITATION}

Wango, K. (2021) “'Drawing with My Students' - The Role of Surrealism in Self-Expression among University Art Students. Analysis of Selected Surrealistic Work by Fourth Year Students at Kenyatta University", International Journal of Advanced Research, 3(1), pp. 1-19. doi: 10.37284/ijar.3.1.272.

\section{IEEE CITATION}

K. Wango, “'Drawing with My Students' - The Role of Surrealism in Self-Expression among University Art Students. Analysis of Selected Surrealistic Work by Fourth Year Students at Kenyatta University”, IJAR, vol. 3, no. 1, pp. 1-19, Feb. 2021.

\section{MLA CITATION}

Wango, Kamau. “'Drawing with My Students' - The Role of Surrealism in Self-Expression among University Art Students. Analysis of Selected Surrealistic Work by Fourth Year Students at Kenyatta University". International Journal of Advanced Research, Vol. 3, no. 1, Feb. 2021, pp. 1-19, doi:10.37284/ijar.3.1.272.

\section{INTRODUCTION}

The engagement with surrealism is always refreshing and fascinating in terms of the ability for one to draw upon their inner thoughts and hence express themselves freely without the inhibition of the usual artistic boundaries of composition and logical reasoning. Elements of what can be described as indicators of hidden 'inner truths' as the artist would wish to identify them are perhaps best expressed through surrealism. This is because surrealism offers the opportunity and freedom to delve into an environment devoid of rational thought processes and opens the way for nonconformity. Student artists are able to delve into the unconventional, the unreal and the bizarre. This is achieved through the exploration of dream-like imageries that flow in the unconscious mind. The lapse of time in-between the state of dreaming (the subconscious) and waking (the conscious) can be tricky and the students themselves have talked of the ability to vividly recall a dream-like situation. Tarrab (2013) observes that;
While many may neglect or underestimate their dreams or view them as random firings of their subconscious, dreams do indeed possess significant meaning. Your nightly reveries accurately portray your deepest thoughts and feelings. Emotions are amplified in dreams, and people are driven into a more uninhibited state of mind.

These imageries are formulated in the mind and manifest themselves when the mind is placed in a certain mode. This suggests that the content of these dream-like imageries perhaps contains elements of truth that may relate to the viewers' individual life experiences.

In view of all this, students are encouraged to harness their own surrealistic ideas based on environments that spur unconscious imageries. They are made to comprehend that unlike other aspects of art, they cannot derive surrealistic ideas simply from the exploration of common themes and subject matter; their work has to emanate from their own individual human experiences embedded in the unconscious mind and which then manifest themselves in their dream-like imageries that flow 
in their minds. These resultant thought processes are not the same as those that emanate from the conscious mind, which are usually re-arranged, compartmentalised, rationalised and logically placed within the strict boundaries of artistic composition. Students are encouraged to immerse themselves in their own freedom of thought and delve into a mode of self-expression that is blunt and fulfilling.

In the context of this paper, their own work has been preceded by lively class discussions that spur their imagination and draw their attention to how their own brains operate and generate visual imageries that can then be expressed artistically. The student artists themselves have presented synopses of their work and their comments are included in this paper almost verbatim. There is no expressed artwork that bears no basis; it must contain an element of 'found truth' that is identifiable and upon which one can draw an association or inference, however remote or far-fetched. The synopses help to glimpse into the workings of the students' minds so as not to lose focus on the basis of their own reflections that underscores the creativity of their work. This is also an important channel of understanding the way students think and subsequently, how they formulate their creative process.

While the student artists may certainly not adopt Salvador Dali's Paranoiac Critical method in their work, they have attempted to exploit the dictates of their unconscious life experiences and render these in an artistic way. In this way, they have come up with some pieces that are quite profound to the viewer. Hilden (2020) observes that surrealism provides "the opportunity to escape external structures to peer into unconscious interiors and explore what's hidden there. It implies big questions about the nature of accepted reality, and urges viewers to redefine themselves based on their own internal worlds."

\section{ESSENCE OF SURREALISM}

\section{Description}

Preceded by Dadaism, Surrealism was founded as an artistic/literally movement by the poet André Breton in 1924 in Paris, France. In its artistic sense, surrealism is "breaking down the boundaries of what is considered to be normal" (Rippingham, 2019). The general term 'surreal' refers to something that is bizarre and removed from the normal realm of reality and hence refers to having the qualities of surrealism. "The word 'surreal' is now commonly used as an adjective to describe the unusual or unexpected" (Ortolano, 2017). The normal realm of reality is anchored on the conscious mind. Surrealism is anchored on the unconscious mind and, therefore, generates an 'alternative reality' which then to the normal eye, is often seen to be bizarre. The formative surrealists perceived the conscious mind as embedded in its rationality and meticulous order, as too constraining or prohibitive; the unconscious mind with its 'superior reality' therefore needed to be set free and explored. Surrealism, subsequently, involves the exploration and depiction of the uncensored thoughts and dream-like imagery that manifest and flow in an Artist's mind, thereby, initiating a body or work that contains significant creative freedom removed from the constraints of the regular subject matter. In this sense, surrealism presupposed that people usually interact only with a surface reality; but in essence, according to the argument of Sigmund Freud, there existed another form of hidden reality embedded in the 'deep-seated secrets and desires of the unconscious mind'. Surrealists in the $20^{\text {th }}$ century subsequently "rebelled against convention, moral codes and the inhibitions of the conscious mind." (Craven, 2019)

According to the Surrealist manifesto written by André Breton in 1924, surrealism has been defined as "Psychic automatism in its pure state by which we propose to express- verbally, in writing, or in any other manner- the real process of thought. The dictation of thought, in the absence of any control exercised by reason and outside any aesthetic or moral concerns" (Moffat, 2011). The formative rationale that gave rise to surrealism was propagated by André Breton who was greatly influenced by the psychoanalytical work of Sigmund Freud. Breton believed that the unconscious mind was the source of artistic creativity and that dreams were, subsequently, an integral part of this creativity. Diametrically opposed to rationalism, the surrealistic movement proposed that the superior qualities of the irrational and unconscious mind that had hitherto been suppressed by the intellectual dispensation of the $17^{\text {th }}$ and $18^{\text {th }}$ centuries be 
accorded their due prominence. "Surrealism's goal was to liberate thought, language, and human experience from the oppressive boundaries of rationalism" (Mann, 2016). Breton himself described the merging of dreams and reality as "a kind of absolute reality, a surreality" (Mann, 2016). In reference to Breton's work, Francis Rosemont states:

Contrary to prevalent misdefinitions, surrealism is not an aesthetic doctrine, nor a philosophical system, nor a mere literary or artistic school. It is an unrelenting revolt against a civilisation that reduces all human aspirations to market values, religious impostures, universal boredom and misery (Wilson, 2018).

Others have described surrealism as a movement in Art "in which the artist attempted to portray, express, or interpret the workings of the subconscious mind by using the evocative juxtaposition of incongruous images in order to include unconscious and dream elements" (Daigle, 2013). Surrealism can broadly be understood from two perspectives of execution or trends; figurative surrealism and Biomorphic surrealism. Figurative, or representational surrealism, features recognisable representational art which though dream-like, uses elements of distortion on forms that bear techniques of realism. This rendition of surrealism was popularised, to a significant extent, by Giorgio de Chirico. "Like de Chirico, figurative surrealists used techniques of realism to render startling, hallucinatory scenes" (Craven, 2019). Biomorphic, or abstract surrealism, includes significantly abstracted forms which are not instantly recognisable but still refer to nature as well as the human form. Craven (2019) notes that "Biomorphic (abstract) surrealists wanted to break entirely free from convention. They explored new media and created abstract works composed of undefined, often unrecognisable, shapes and symbols."

Some of the most outstanding artists associated with surrealism include André Breton, Salvador Dalí, Joan Miró, Francis Picabia, Marcel Duchamp, Frida Kahlo, Max Ernst, Yves Tanguy, René Magritte, Pablo Picasso, André Masson, Man Ray and Meret Oppenheim (Mann, 2016; Craven, 2019).

\section{Surrealism and Self-expression}

As already observed, surrealism in its inception sought to move away from the dictates of the conscious mind. Its proponents like André Breton insisted on the reliance upon 'the process of thought' that is removed from the influence of rationalism and the inhibition of the moral code. Self-expression, therefore, in the context of its conventional description, has to seem to align itself to this dispensation of thought that is devoid of the rational world of the conscious mind. This transformed mode of self-expression then translates into a new kind of truth, an 'inner truth' that is manifested in the artwork. The difference between this mode of self-expression and the conventional description of self-expression is that the artist now interrogates and attempts to interpret the depths of dreams and the unconscious mind which according to Breton needed to be interpreted. "The writings of Sigmund Freud suggested that higher forms of truth might be found in the subconscious" (Craven, 2019)

\section{Impact on the Audience or Viewers}

The impact of surrealism on the audience or viewer can be both drastic and profound, given its nature of anti-rationalism. Most people are used to some element of reason and rationality in works of art, but surrealism is based on dream-like imagery based on the unconscious mind; hence the particular artist has the freedom to express any of his/her flowing imagery as it manifests in the mind and, therefore, does not need to conform to any creative norms. Beyond the irrationality, bizarreness or absurdity of the visual encounter with surrealistic work, viewers are able to find a point of convergence once they have comprehended the underlying surrealistic principles. The work featured in this paper has shown that surrealism can also lead or 'translate back' to rational thought and provide a meaningful interpretation or insight into a given aspect of human endeavour. As will be evident, this is important because it suggests that the viewers can derive a message from surrealistic work implying for instance, that visual irrationality can convert to mental rationality. Surrealistic work can lead the viewer to re-examine their own essence from the way they react to the work itself. Arguing that surrealism is really about the impact on the viewer. Hilden (2020) suggests that upon viewing 
surrealistic work, a viewer should ask himself or herself, "what could be concealed in my subconscious that would make me react this way? Who am I, and why am I feeling like this? And what does this tell me about the way I relate to the outside world?

\section{Relevance of Surrealism}

It can be argued that by the very nature of surrealism, its freedom of technique and aspects of its fundamental execution still remains attractive to contemporary artists. The focus on dreams and dream-like imagery that gives rise to the exploration of the unconscious mind, fantastic imagery and delving into the absurd provides the kind of freedom that still spurs the imagination of artists today. The notion that dreams can be, and should be analysed opens a new frontier of possibilities in selfexpression. Mann (2016) observes that "the Surrealist focus on dreams, psychoanalysis, and fantastic imagery has provided fodder for a number of artists working today". In a contemporary context, therefore, the aura of expressive freedom provided by the tenets of surrealism such as the exploration of dreams, which is very personal, still attracts many artists. It has been noted that:

Surrealism had a major impact on modern art and continues to be seen across creative fields including film, literature, graphic design, fashion, and visionary art. This is a testament to the freedom unleashed by surrealism's initial mission, whereby artists and writers may convey their own uniquely individual thoughts, feelings, and innermost drives through creative means. It loosened the field of possibilities and promised perpetual fodder to mine (Wilson, 2019).

In this regard, artists still pursue surrealist ideals in a modern dispensation by using highly symbolic imagery that triggers emotive thoughts and reactions from their audiences. In so doing surrealism enables viewers to be more accommodative of their own interpretation of what surrealistic work means in reference to their world. In underscoring the essence of surrealism today, it has been noted that:

The boldness of the artists involved with the Surrealist movement caused a giant domino effect of creativity and self-expression portrayed into art. Without the boldness to go against what society told them was right, we possibly wouldn't have the creativity and freedom of expression in our works that we have today (Daigle, 2013)

\section{ANALYTICAL FRAMEWORK}

In the analysis of surrealistic work, this paper uses the following guidelines that constitute a framework of internalising the content and context of any surrealistic work, particularly in drawing and painting. Surrealistic work, by its nature and execution, does not bear or manifest the normal parameters of analysis as all other regular forms of artwork and, therefore, its analysis is somewhat different in approach. It bears its own spontaneity, it is dream-like and draws from the unconscious; not the conscious. It can be bizarre and startling and may not conform to the normal compositional ground rules of other works of art; it often embraces false perspective. An analytical framework is, therefore, best derived from the key features of surrealism which are then woven together and considered holistically to guide the analysis of any surrealistic work. The analytical framework is, subsequently, based on the following key tenets which are, however, not applied singularly, but may appear inter-related. As has been observed the surrealistic work featured in this paper is specific to drawings and may not involve all the key features.

\section{Use of Metaphor and Symbolism}

In examining surrealistic work, it is important to understand what inspired surrealists in the first place, "they developed techniques to bring metaphor and meaning into their work. The obvious may have been stated, but the meaning to Surrealist art was symbolic and often open to interpretation" (Moffat, 2011). Subsequently, in analysing surrealistic work, the use of metaphor and symbolism is an important component of the derivation of meaning, which at the same time, opens the work to multiple interpretations.

\section{Use of Dream-Like Imageries}

Analysis of surrealistic work also includes exploration of the meaning of dreams depicted through the dream-like imageries. Sigmund Freud once said, "A dream that is not interpreted is like a 
letter that is not opened" (Moffat, 2011). He was referring to his method of psychoanalytical interpretation which could be used to focus upon and shed light upon the unconscious. This means that dreams that give rise to unconscious imageries which the artist depicts should themselves bear some kind of meaning which must be analysed and understood as a new reality.

\section{Use of Spontaneity and the Element of Automatism}

The term automatism "has been adopted in the art world, and adjusted to mean creating art without conscious thought. The unconscious mind, believed to withhold creative potential, is accessed during automatism" (Wilson, 2018). Automatism occurs when an artist uses a technique which suggests that his or her work has bypassed a conscious or rational thought process. The final product, hence, contains forms or images that emanate from the subconscious mind without the artist's control. This forms a key aspect of surrealism which focuses on capturing the mind's deepest thoughts automatically as they manifest.

\section{Use of Distorted Figures and Biomorphic Shapes}

Surrealistic work may feature images that include distorted figures of living forms as we know them. This distortion helps to create the kind of imageries synonymous with dream-like sources, the uncanny, the absurd and the irrational. Biomorphic images are abstract in execution which means they bear no naturalistic imitation of anything familiar in the real world but still refer to living forms reminiscent of nature as well as the human body.

\section{Personal/Cultural Iconography}

Personal iconography refers to symbols and ideas that bear personal meaning. The use of personal iconography is a usual component in the construction of surrealistic ideas and is easily identifiable. Cultural iconography refers to aspects of cultural symbolism that appear in an artist's work as an integral part of the juxtaposition in surrealism.

\section{Illogical Juxtapositions and Bizarre Assemblages}

Illogical or irrational juxtapositions refer to bringing together or overlapping completely unrelated images into a composition in order to lay emphasis on a desired dream-like concept, particularly in the construction of metaphor. This is used to draw the viewer's attention to the possibilities of new visual inter-relations and to view things in a different light in the creation of new meaning.

\section{Visual Puns}

According to Moore (2017), visual puns have existed since the beginning of time and continue to affect and innovate our critical, conceptual, and creative thinking today. The use of surrealistic metaphors and symbols is closely related to the use of visual puns since they are all visual pattern identification tools. Visual puns help the artist to underscore a sense of the absurd in a surrealistic piece. Referring to the artists of the Dada Movement, Moore (2017) writes that:

With their visual puns and picture play, paved the way to help artists "explore the spontaneity of intuitive expression," which is now "firmly embedded within the consciousness of the individual artist." Therefore, puns exist not just for our amusement, but can also inspire creativity, as well as critical and conceptual thinking 
ANALYSIS OF WORK

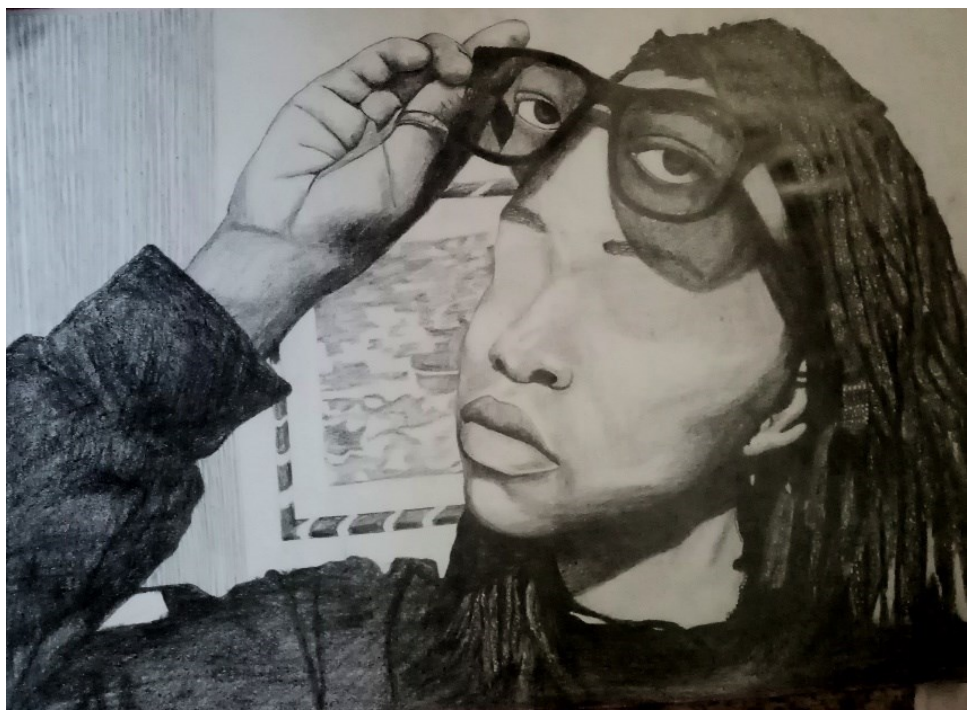

Plate 1: Ng'aru Brian (2020)

'Safe place'

Pencil - 29 x $42 \mathrm{~cm}$

Plate 1. Eyes are strong nonverbal channels of communication. Eye contact is a strong tool for establishing trust between two people when communicating. The composition describes how people use sun-glasses to conceal their state of being, emotions and other physical issues. People wear sunglasses to conceal various situations (Student artist).

Eyes are a very strong descriptive factor of character and personality. They are the single most important factor of facial identification and recognition; remove the eyes and you create a new indiscernible creature. The surrealism is depicted through the sealed eye sockets and eyes that are shifted away from their normal placement on the facial structure. Subsequently, the essence of a facial character, including its physical beauty and completeness, is grossly interrupted. Most significantly, the eyes with their character and personality, are deliberately shifted away within the sunglasses and seem to float in an abnormal space, creating a new spatial arrangement that is hollow, devoid of character and bizarre. This is consistent with surrealistic principles and is perhaps a consequence of a dreamlike image that flashed in the artist's mind.

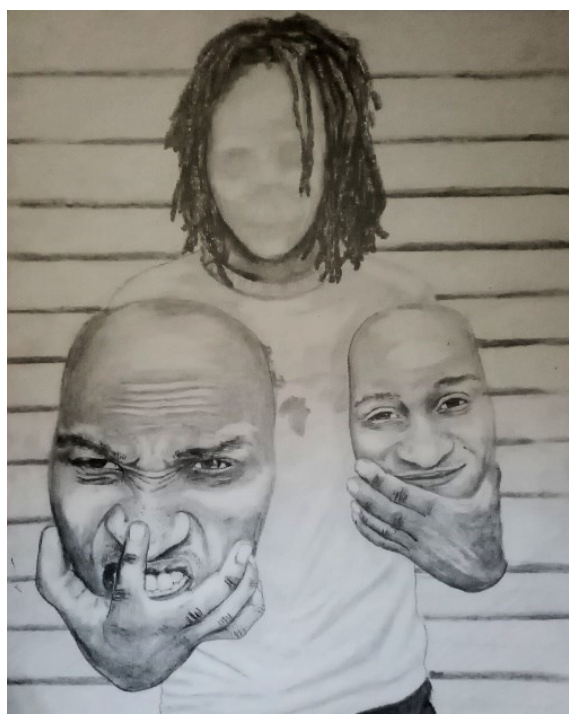

Plate 2: Ng'aru Brian (2020)

'Myself and 1'

Pencil - 42 × $29 \mathrm{~cm}$

Plate 2. The artist is addressing split personality. He tells a story of how he is forced to wear different personalities in different situations while dealing with a judgmental society. It is an internal conflict he faces while thinking of how to approach life; when to toughen up and when to wear a smile (Student artist).

The drawing depicts the 'enigma' of the self. Due to the complexities of life, individual inadequacies and insecurities, some people are unsure of how to anchor their personalities or even how to define themselves. This compels them to present themselves differently to suit the circumstances of the moment; hence they exist in a state of dilemma. The surrealism is based upon the dilemma of which face adorning in order to meet the challenge of the moment. This dilemma is presented as a bizarre depiction of a faceless individual holding prospective faces in his hands. Through this surrealism, the viewers are encouraged, therefore, to be worthy determinants of their content of character as a basis of defining their own self-worth. 


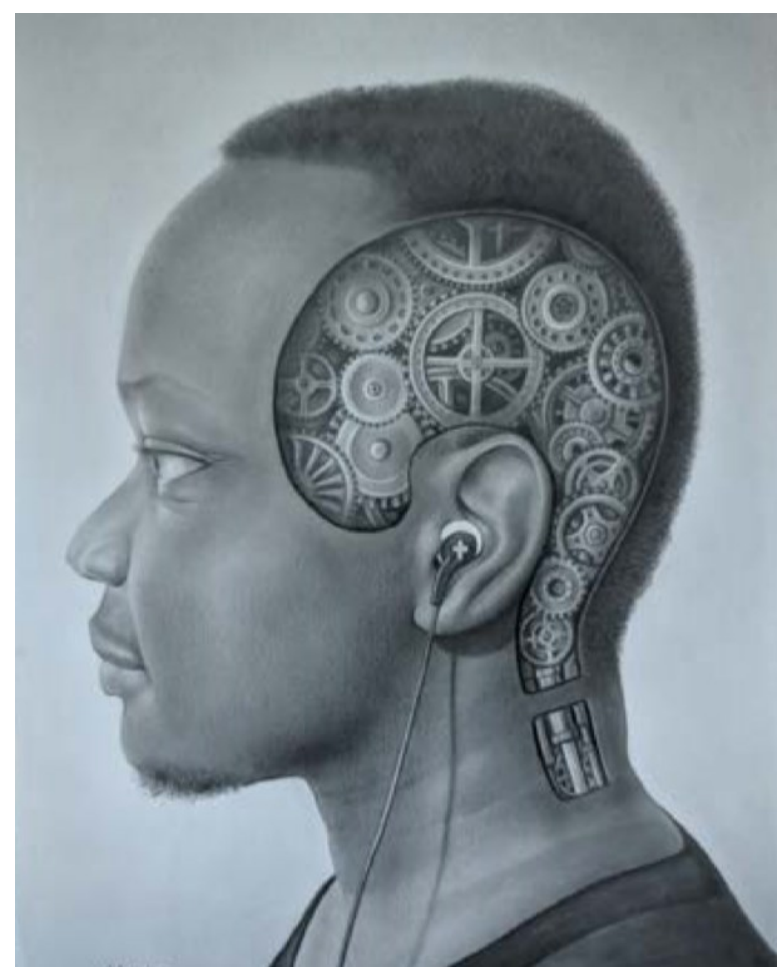

Plate 3: Kamau Edward Waihenya (2020) 'Chronos'

Pencil - 42 x $29 \mathrm{~cm}$

Plate 3. Time and mortality. I am just but minutes, little things. I walk a path unseen, never going backwards, and how I use myself, I must one day tell. Many have come before, many have been. Where will I be, when will it end? All in all, time is a friend, yet too slow as I wait, too swift when I'm afraid, too long as I grieve and too short when I rejoice (Student artist).

The drawing underscores the essence of time and how it ticks by in the brain, which is the nerve centre of the body; just like the cogs in a watch. When one observes the cogs move in a methodical, mechanical synchrony, the ticking of time bears an eeriness that is a constant reminder of the fragility of life and the urgency of time itself. If time ticks away in minute seconds, the obvious concern then, is how best it is utilised. The surrealism is the brain appearing like the cogs in a clock, personifying time. The wisdom of its usage, or lack of it, is placed in the form of a question mark which signifies that the onus of its management is upon the wisdom of the individual.

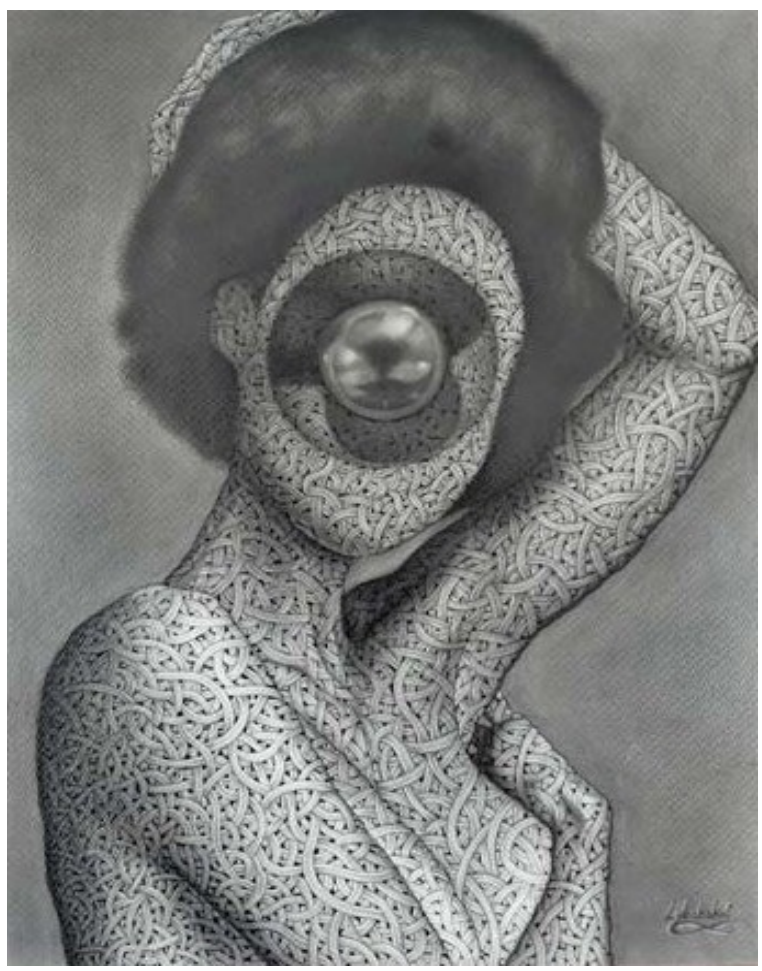

Plate 4: Kamau Edward Waihenya (2020)

'the black pearl'

Pencil - 42 × $29 \mathrm{~cm}$

Plate 4. The human fabric with all its complexities, wrapped beneath those tendrils and connections is a jewel unlike any other. Just like clams or oysters, we make our own pearls, layering them with smooth sheets of our very own essence. Underneath the hard shells people display, we cradle the singular gem of our existence. Just like Jack Sparrow in the movies, I too search for the black pearl. In the darkness of my dreaming a light still shines, reflections on the surface of that lustrous sphere (Student artist).

This intricately detailed drawing underscores the continuous search for the best in ourselves, our individual black pearl, often hidden beneath our individual complexities. Because of its natural value, the pearl has become synonymous with something rare, of the finest quality, admirable and infinitely valuable. The surrealism in the drawing depicts the pearl appearing in the head in place of the face to signify the profoundness of the value of our individual self-worth. When this is galvanised and well harnessed, then we produce and exude the 
best of ourselves, signifying content of character or human goodness; just like an oyster produces a pearl in its mantle.

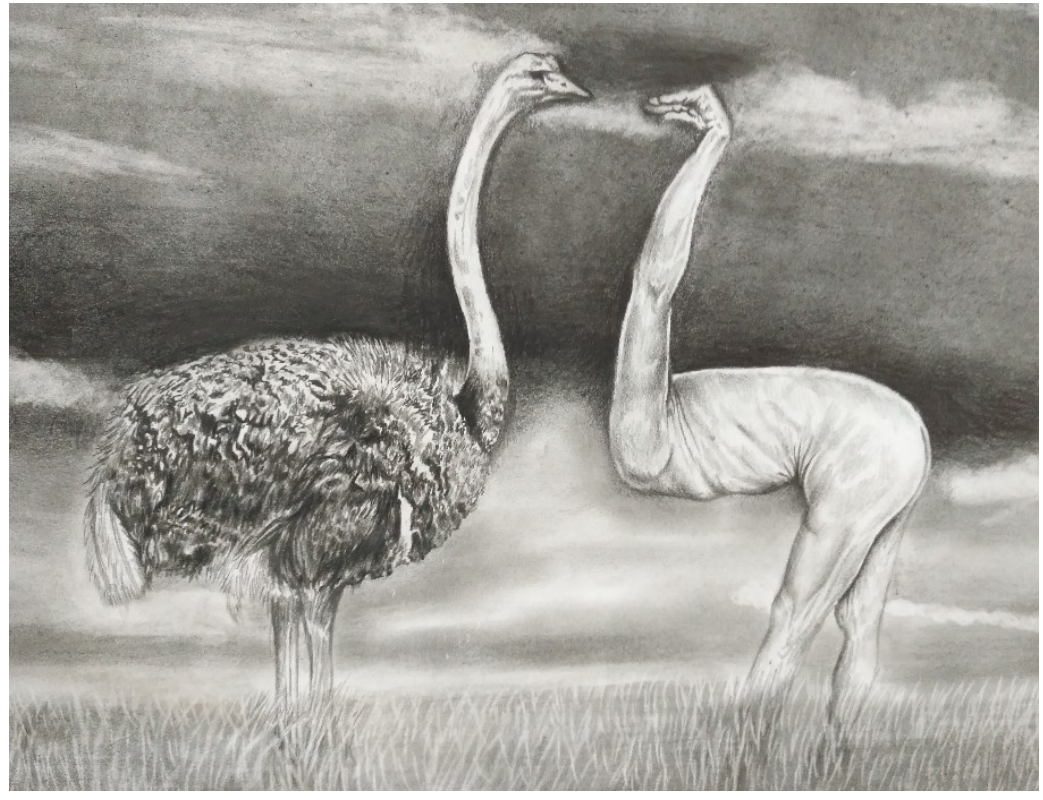

Plate 5: Norbert Yonga (2020)

'Pretense'

Pencil - 29 x $42 \mathrm{~cm}$

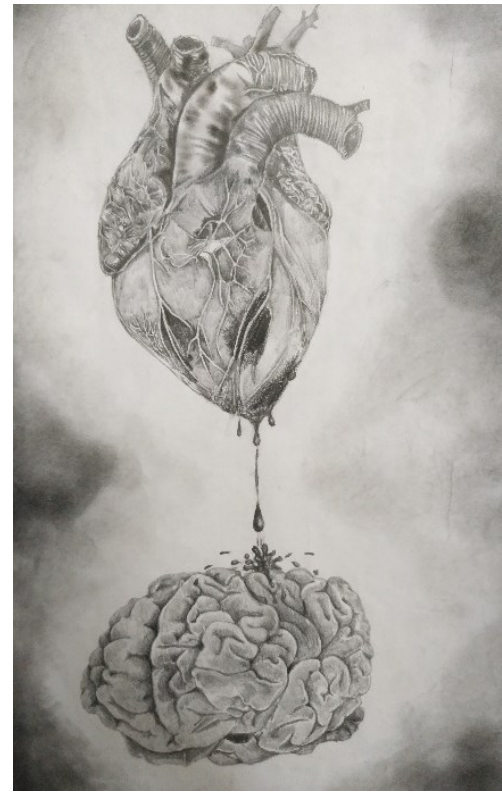

Plate 6: Wewa Gregory (2020) A stain on my brain' Pencil - 42 × $29 \mathrm{~cm}$
Plate 5. This piece depicts an ostrich in its natural environment next to a human form contorted deceptively in order to approach the ostrich. It is meant to show that often, many people pretend to be something they are not in order to fit in certain circumstances or measure up to people in order to seek acceptance. The lesson behind this is that people should be aware of pretenders and see-through into their motives (Student artist).

The tendency of an individual towards conformist mimicry merely to please and gain acceptance from another is deplorable just as it is demeaning. It is presumed that all human beings in interacting with each other start from the point of individual definition and strength of character as a common springboard towards mutual understanding. The pretence of character is not only unwarranted but also deceitful and counter-productive. The drawing shows the contorted human figure as having no head because in the quest to become an ostrich, the head is inconsequential. The student artist uses pencil to execute textural effects and background contrasts to highlight the very expressive forms.

Plate 6. This drawing shows human emotion. It is logic versus emotions. I portray how people make decisions, particularly in matters of love, which they later regret, having realised their folly. The heart represents the emotions while the brain represents the logic (Student artist).

The symbiotic relationship between the emotional functions of the heart and those of the brain has been the subject of infinite intrigue through the ages. It has been a matter of intense debate about which one of the two holds sway upon the other; which controls the other and which ultimately is more influential in the way human beings perceive, process and determine matters that fundamentally affect their lives, including matters of love. 


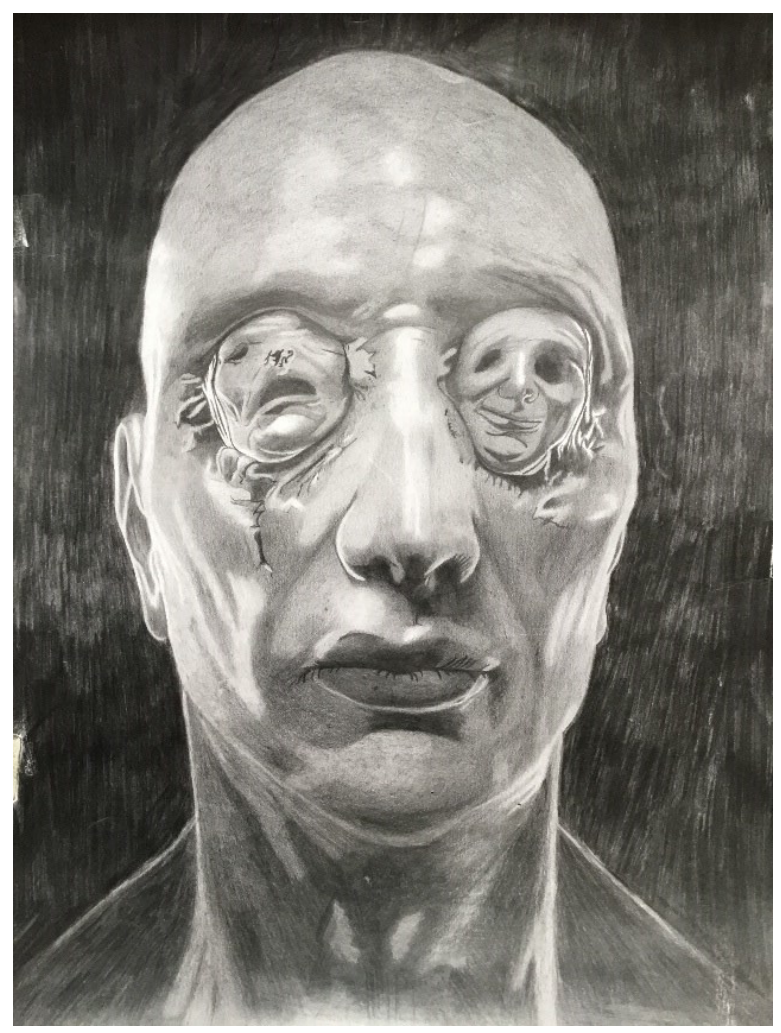

Plate 7: Mark Ian (2020)

'Scar'

Pencil - 42 × $29 \mathrm{~cm}$

Plate 7. This is a drawing of a soldier's scarred face. His face also has smaller faces in place of his eyes, and they represent the memories he has of war. The art tells of the pain soldiers go through after they have served in war. Some memories haunt them badly while others fill their hearts with smiles (Student artist).

The surrealism is in the absent eyes where other smaller faces appear instead, representing the flowing images that constitute his wartime memories. The soldier's face is an expression of infinite torment yet borne in a rather strange calmness. The student artist uses light and dark as an effective tool to depict the face and focus the viewers' eyes on the surrealism.

Plate 8. This is a drawing of a lady who seems to be in a serious meeting with herself. 'Shauri lako' is a Swahili word that translates to 'advice upon self'. We humans summon ourselves on personal meetings as a form of self-assessment.

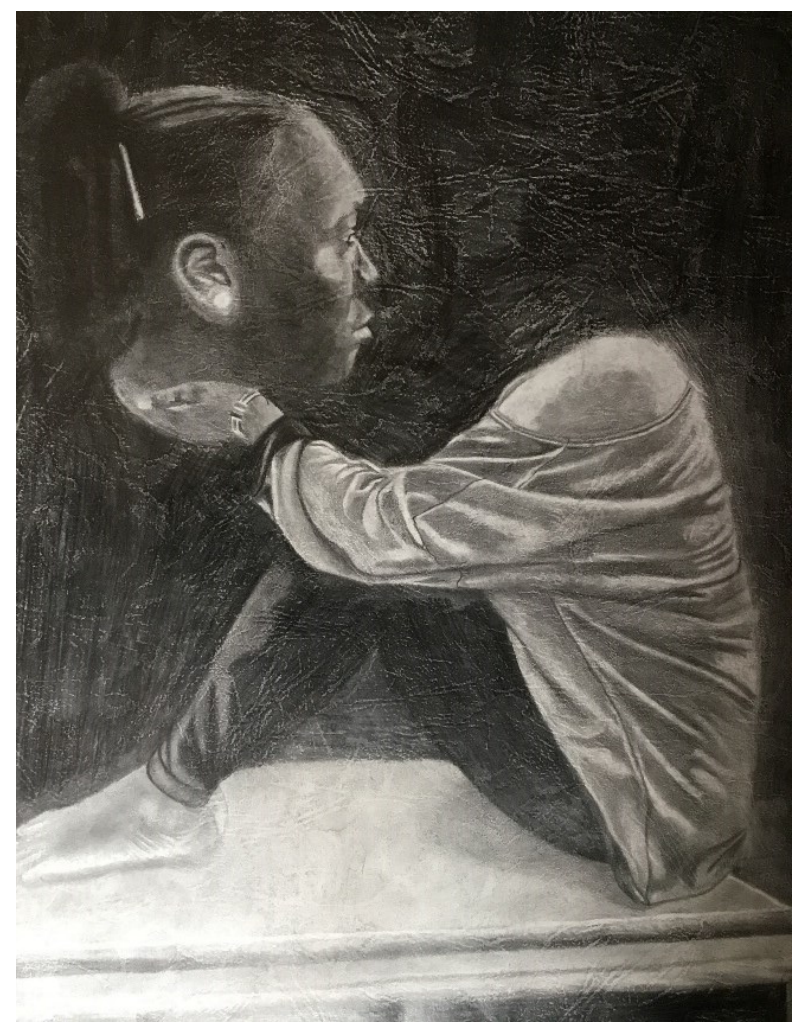

Plate 8: Mark Ian (2020)

'Shauri lako' (your own advice)

Pencil - 42 × $29 \mathrm{~cm}$

We have the ability to talk to our inner selves and mend our ways or improve (Student artist).

This profound drawing is the epitome of selfreflection. A human being takes a little quality time to vacate her body in order to face and address 'herself'; to interrogate her own conscience and her personal essence. In such circumstances, it is only the individual who is capable of self-assessment and delving into his or her own body and soul; no human being can do that for another. The bizarre drawing denotes the possibility that such ardent need for selfassessment is actually essential and wise. It exhorts the audience to take some quality time off every once in a while for a blunt reality check. The student artist uses light and dark effects to emphasise pertinent parts of the composition such as the naturalistic folds on the clothes and the posture of the female figure. The effect is also used to focus upon the surrealism of the headless body and the lone head with the gazing face held in its hands. 


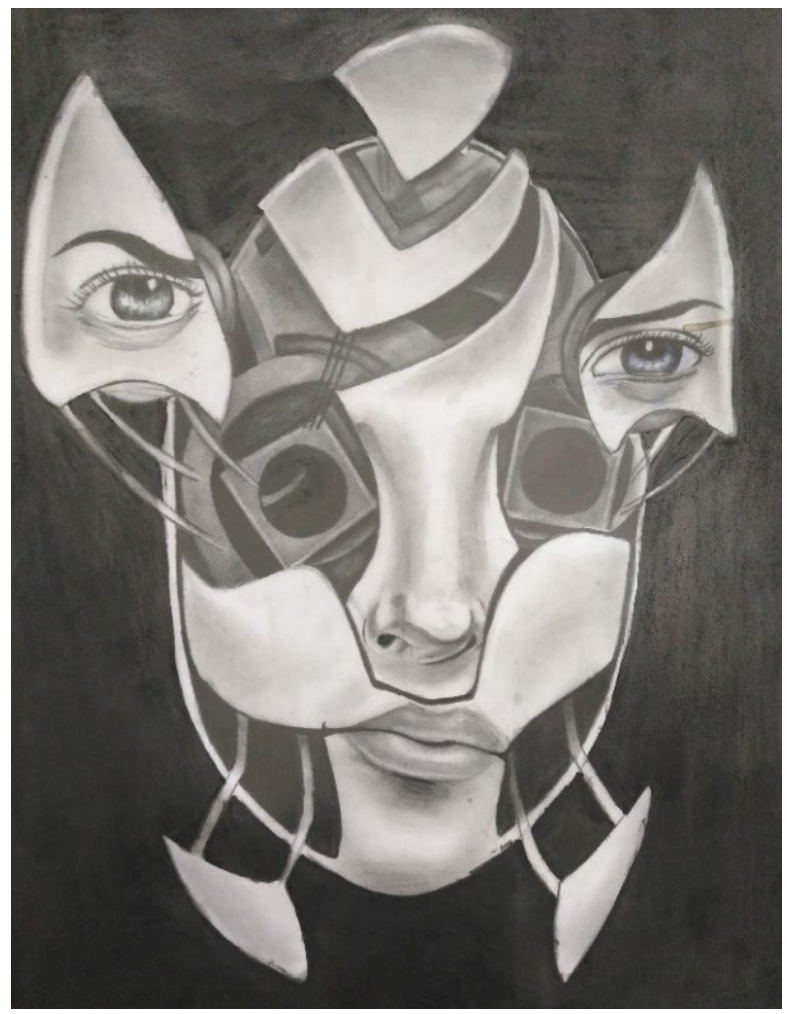

Plate 9: Davis Mutwiri Kirimi (2020)

'Self-transformation'

Pencil - 42 x $29 \mathrm{~cm}$

Plate 9: The face can transform into parts of a machine which represents the current generation where we have human beings of all races, religion and class. Akin to machines, we work mechanically and are filled with equally blank happiness or no happiness at all (Student artist).

The face is depicted in a semi-abstract drawing that shows the disassembling of mechanical parts of the face reminiscent of the working of a machine. The disassembled face represents the breakdown of the

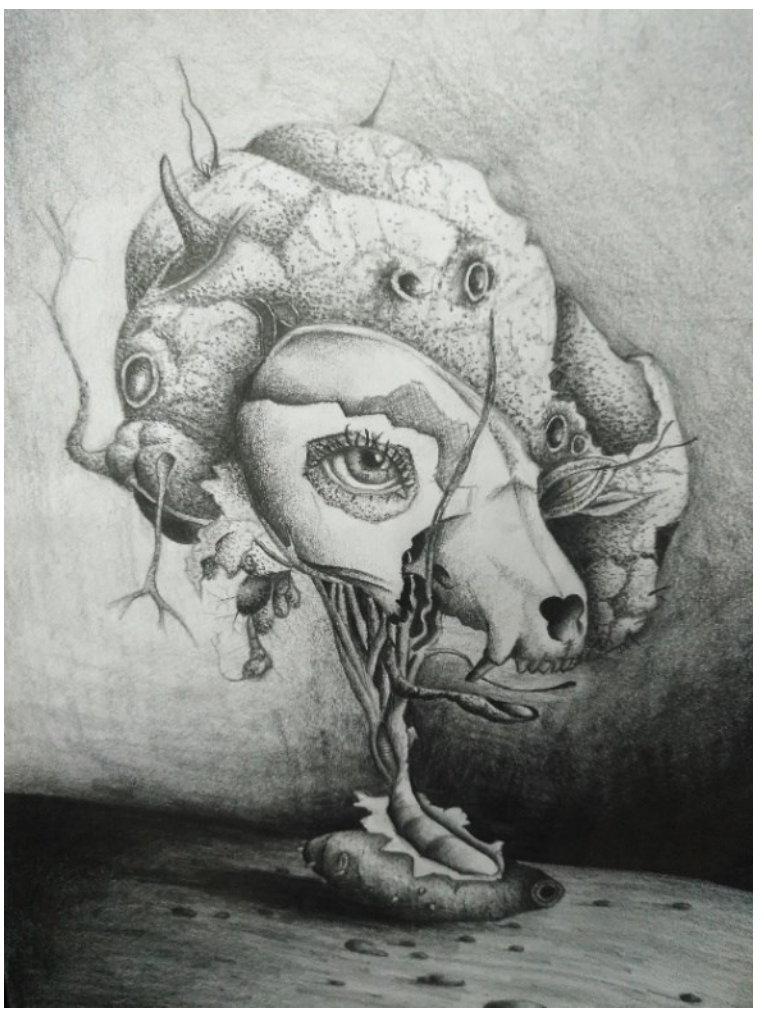

Plate 10: Lusigi Nelson (2020)

'Expectations'

Pencil - 42 × $29 \mathrm{~cm}$

whole, meaning the breakdown of individual happiness.

Plate 10: Just like every situation and every activity one is involved in, there are always expectations on the final outcomes. It is never prudent to always expect positive outcomes from all that comes our way. Sometimes life will fail to be what we want it to be.

In this grotesque drawing, what sprouts from a shoot of a plant is not necessarily what is envisaged or expected. 


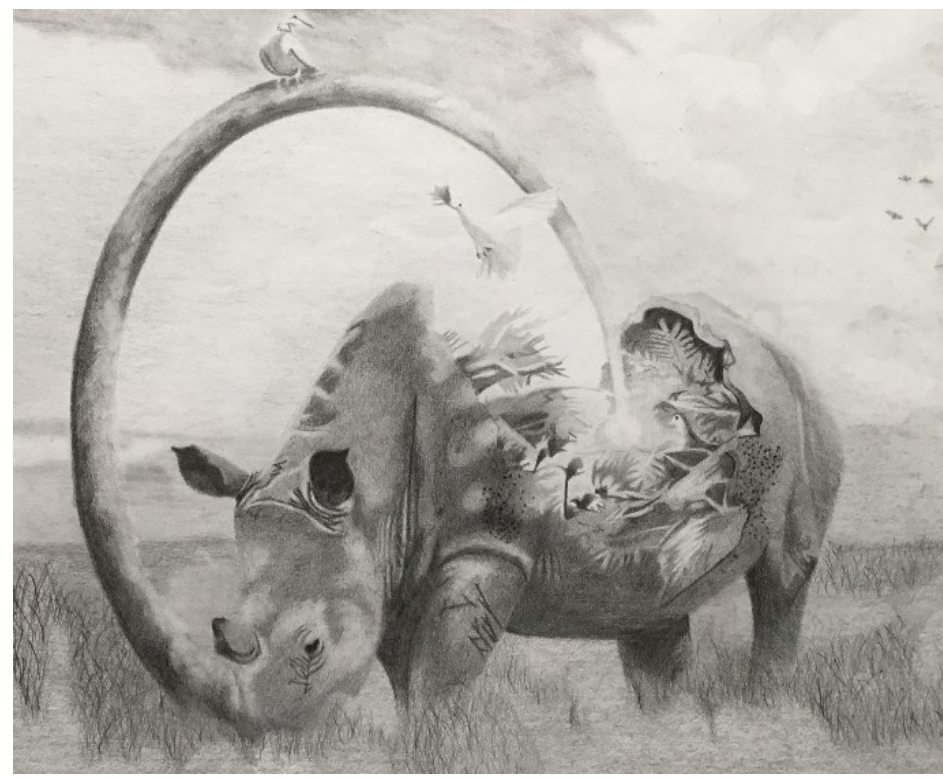

Plate 11: Mark Ian (2020)

'Just nature'

Pencil - 29 x $42 \mathrm{~cm}$

Plate 11: This is a drawing of a rhino that is grazing. The drawing tells a story of the interdependence that exists in life. For one to grow strong and powerful, there has to be helping hands along the way. Inside the rhino's belly, there is life. From what he is feeding on, he takes life as well as gives rise to some other life hence the balance (Student artist).

The strange drawing of a rhino that has access to its own open belly through its elongated horn raises eyebrows. The student artist talks of life interdependence that denotes the cycle of life.

Plate 12: This drawing was inspired by the error page on the Google search engine. When a page you are searching for is missing or has been

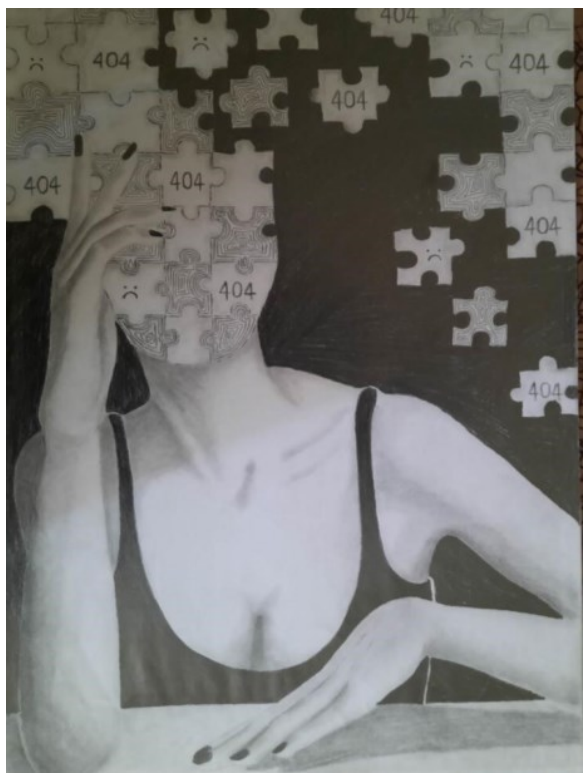

Plate 12: Michelle Tuwei (2020)

'Error 404: Identity not found'

Pencil - 42 × $29 \mathrm{~cm}$

deleted, 'Error 404: Page Not Found' pops up on the screen. This is used in the drawing to portray the feeling of a loss of identity brought about by depression, grief or trauma (Student artist).

The loss of identity can be a long process or can also happen suddenly following a major occurrence or trauma. Loss of identity may be triggered by sudden obstructive changes; such as in the workplace, loss of a job or designation, changes in childhood, in parenthood and in relationships. These changes may leave gaps, deep abysses and empty spaces in one's psyche. The scattered pieces of the puzzle signify the difficulty of trying to find oneself after a period of depression but is also an indication of hope. 


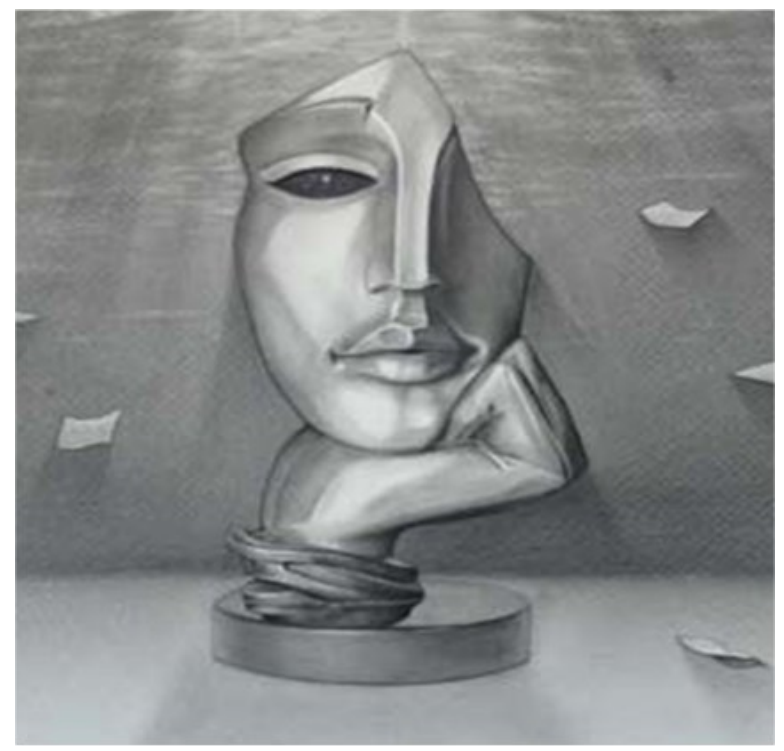

Plate 13: Kamau Edward Waihenya (2020)

'Face time'

Pencil - 42 × $29 \mathrm{~cm}$

Plate 13. In my recurring dreams, there is a familiar face that glows below the surf of my mind. A monument I erected in the deepest, darkest, murkiest parts of my thoughts, where it can only rain light. When my mind takes comfort in shelter of the night, it does its own secret ceremonials enabling me to produce drawings, softly shaded for an audience of one. Hoping they sink deep enough to cover the footprints I leave on the sands of time after visiting the image of her in my mental shrine (Student artist).

The student artist talks of this almost omnipresent image of a woman that regularly appears in his dreams; a secret encourager to his course. Every encounter with this image in the dreams enables the artist to produce drawings that are testimony to that encounter, meant to be for the audience of one, meaning for his consumption only. Hence every night is face-time, a secret rendezvous from which there emerges a covenant between them. The drawing depicts the surrealism of the appearance of the image of this mysterious woman, with her face resting on the palm of her hand in a pose that suggests her regular visitation. Some forms of surrealism are derived from deeply personal experiential imageries or dream-like situations that

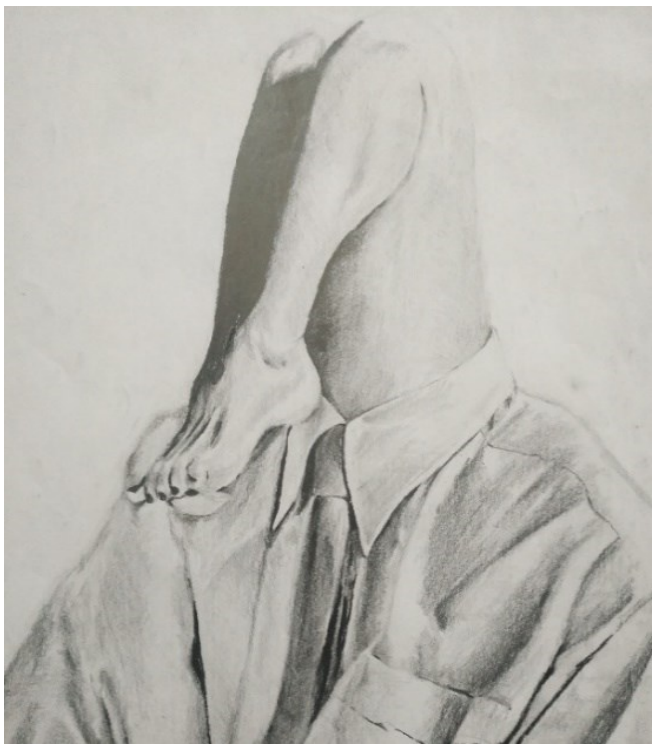

Plate 14: Obwogi A. Mogire (2020)

'What men see'

Pencil - 42 × $29 \mathrm{~cm}$

flow in one's mind; the meaning of which is usually quite vivid to the participant but rather abstract to the viewers. From the description given by the student artist, the development of this piece suggests the use of visual transcription of dreams. He seeks to produce drawings as an automatic record of the dream-like imageries derived from encounters with this mysterious face. He talks of 'deepest, darkest thoughts' and being able to draw images after visitations with the image of the woman's face in his 'mental shrine.'

\section{Plate 14. 'What men see'}

The student artist does not elaborate, but perhaps his drawing does not require any elaboration; it is not an enquiry, it is a statement. The title is conclusive and the drawing itself, bizarre. The placement of legs in place of a head is suggestive of a complete take-over implying that that individual (man) no longer has control of his mental faculties. This dream-like imagery can be as a result of fantasy, but its manifestation is, however, still profound. The viewer may wish to delve into its implication in real life and perhaps wonder if men are indeed so blinded by 'the legs'. 


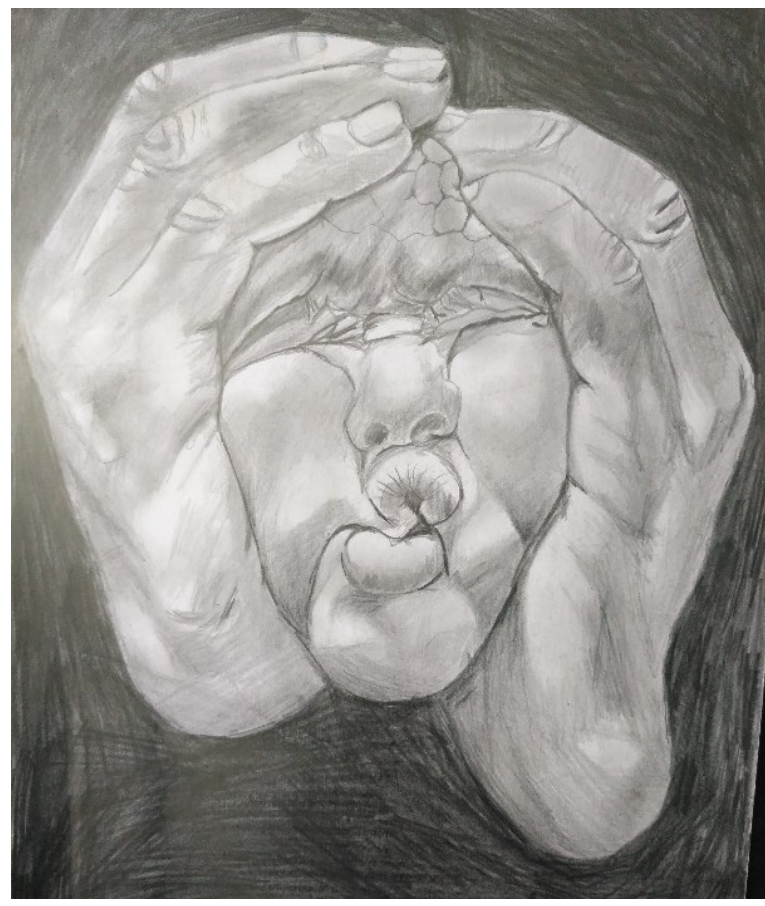

Plate 15: Alubokho Shem Jesse (2020)

'Self-inflicted pain'

Pencil - 42 × $29 \mathrm{~cm}$

Plate 15. Often, we experience pain, but it is up to us to decide how we want that pain to affect us (Student artist).

In a vividly expressive depiction of the torment of mental stress, the student artist utilises the surrealism of oversized hands engulfing the distorted face as well as grasping the entire head, like an unforgiving vice. The surrealistic symbolism is depicted in the afflicted individual seeking relief and comfort from the unbearable torment by resting the head within the grasp of the oversized hands. Perhaps the person is trying to soak away the pain of stress or holding the head together to prevent implosion. The contorted lips and pained, closed eyes are indicative of the magnitude of the predicament.

Plate 16. Every artist dips his brush in his own soul and paints his own nature into his pictures.

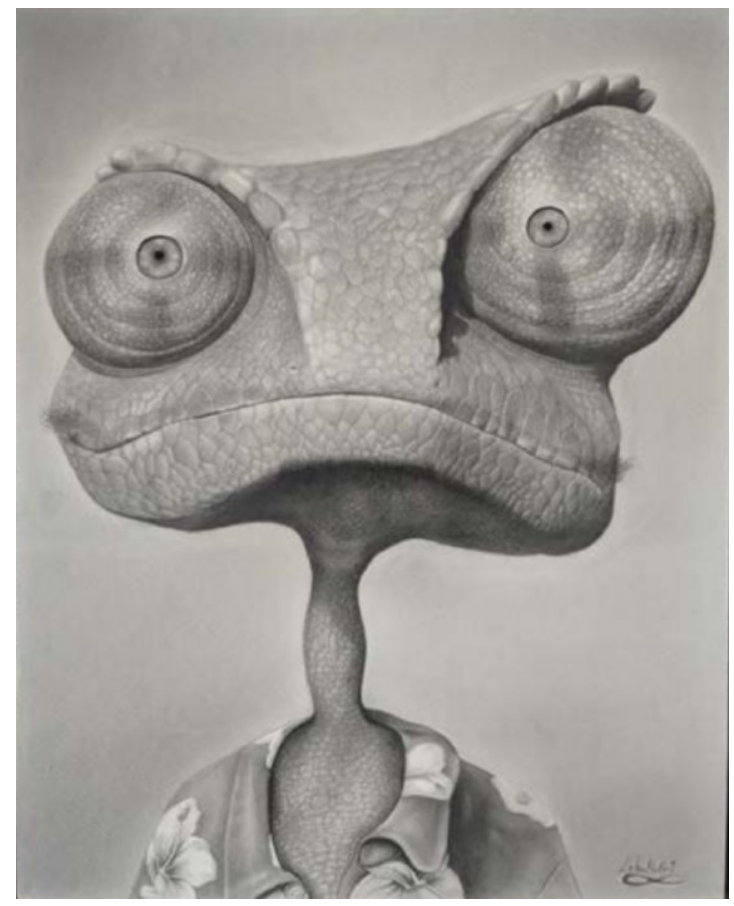

Plate 16: Kamau Edward Waihenya (2020)

'Self-portrait'

Pencil- 42 × $29 \mathrm{~cm}$

I'm a good pretender, won't you come to see my show. I'm not really cool, I do not belong here, and you all clearly do. But I'm a good pretender because I'm just like you. Still insecure behind the scenes. I am the great nothing masquerading as something you can name. Just another marksman searching for his target in the mirror (Student artist).

If every artist dips his brush in his own soul and paints what he or she sees, then the surrealism depicted here could be a glimpse into his or her strange inner nature. This may refer to an inner character that is indiscernible and, hence, difficult to place since it is not compatible with the tenets of normal human character. The surrealism could also refer to the enigma of hidden or alien character that puzzles friends and foe alike when it finally manifests itself in certain equally bizarre circumstances. 


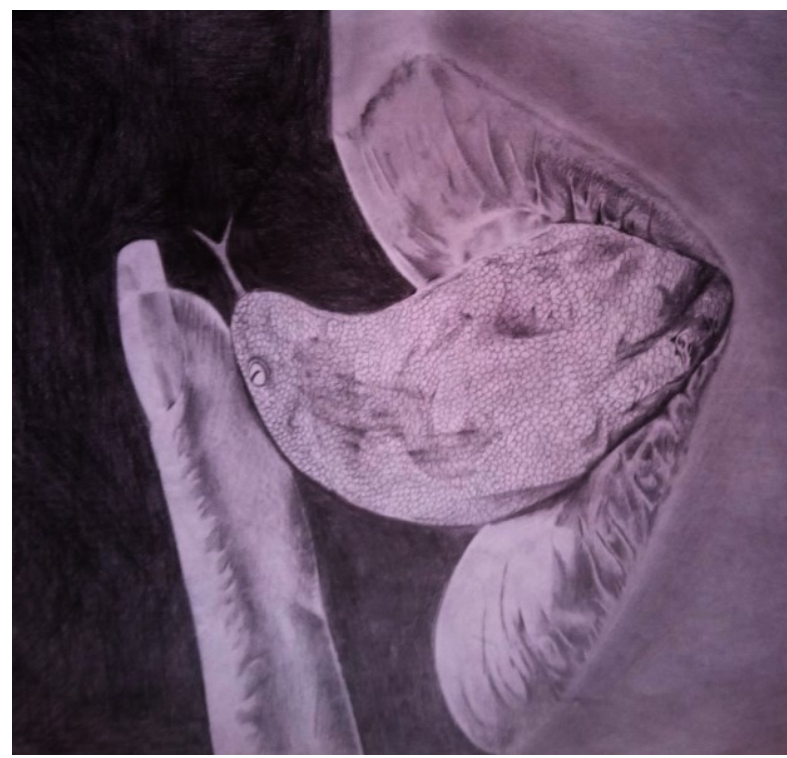

Plate 17: Dennis Kamau (2020)

'Untamed tongue'

Pencil - 42 x $29 \mathrm{~cm}$

Plate 17. Sometimes the untamed tongue is like a poisonous snake that is loaded with the venom of hate, half-truths and gossip. It has the power to destroy lives (Student artist).

The perils of the untamed tongue have been highlighted since time immemorial; it is even a subject of constant caution in the scriptures. Azuka (2020) referring to the biblical text James 3: 2-10, observes that "The tongue is one of the smallest parts of the body described in the scripture as an unruly evil. The description is so because the tongue is not disciplined on its own and is full of "fire of hell' if misused." Focusing on the tongue as an organ, he continues, "The tongue itself is not, by anyway bad. The Lord Almighty made it to serve a definite purpose for man, but the misuse of it is where the problem lies." The surrealism is the depiction of the tongue as a venomous serpent emerging from the mouth signifying complete hypnotic influence upon the mouth and brain. The

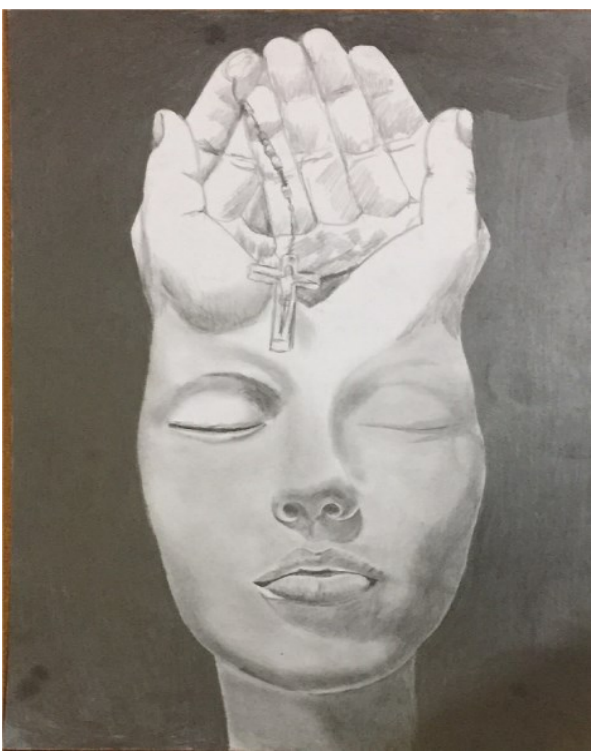

Plate 18: Alubokho Shem Jesse (2020)

'Prayerful'

Pencil - 42 × $29 \mathrm{~cm}$

untamed tongue has long been a subject of conversation in African traditional societal ethos, leadership, role modelling, character formation and the construction of common human decency. All are cautioned from an early age about the folly of engaging an untamed tongue. In African traditional societies, a lot of this caution is contained in proverbs.

Plate 18. When everything seems amiss, we all turn to God as our hope which brings us much needed peace (Student artist).

The surrealism is depicted in the praying hands sprouting from the head signifying total divine faith as opposed to the measured thoughtfulness of the brain at a human level; that divine faith is allencompassing and supersedes human ability. The serenity of the face signifies total submission to divine power and mercifulness as well as the peace it emanates. 


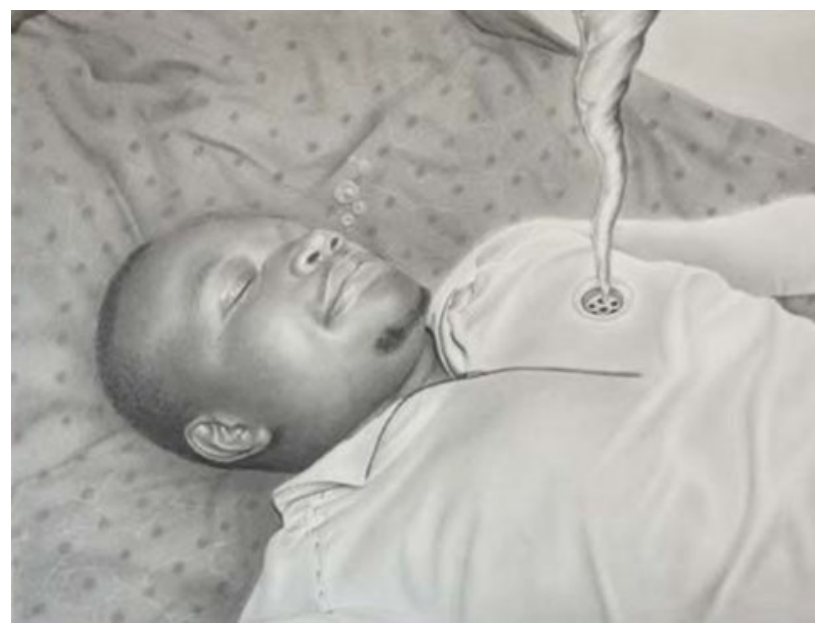

Plate 19: Kamau Edward Waihenya (2020)

'Nirvana'

Pencil - 29 x $42 \mathrm{~cm}$

Plate 19. If people were to perfectly comprehend the world they live in and adequately be enlightened, they would drain away in a whirlwind all that which is not essential from their hearts; it would be akin to achieving the state of Nirvana, a place of peace and happiness where everything that is of this world is drained away from the body leaving behind a blissful existence free of personal desires and earthly suffering (Student artist)

The student artist uses realism in his drawing with the only surrealistic element is shown by the whirlwind draining or sucking away like a vacuum cleaner, all the undesirables from the sink plug on the heart. A sink plug normally drains away from the dirty water. This time it is draining away earthly non-essentials from the inside of the body. The blissful state of Nirvana is itself dream-like and removed from the turmoil of the physical world. From the realistic but serene face of the lying figure (which is a self-portrait), the student artist extracts the imagery of blissfulness as it manifests itself from his subconscious mind.

Plate 20. The drawing is inspired by the tough times of COVID-19 where people have been forced to stay put at home. No one really understands the situation; hence, the people offer no explanation, only suffering its perils (Student artist)

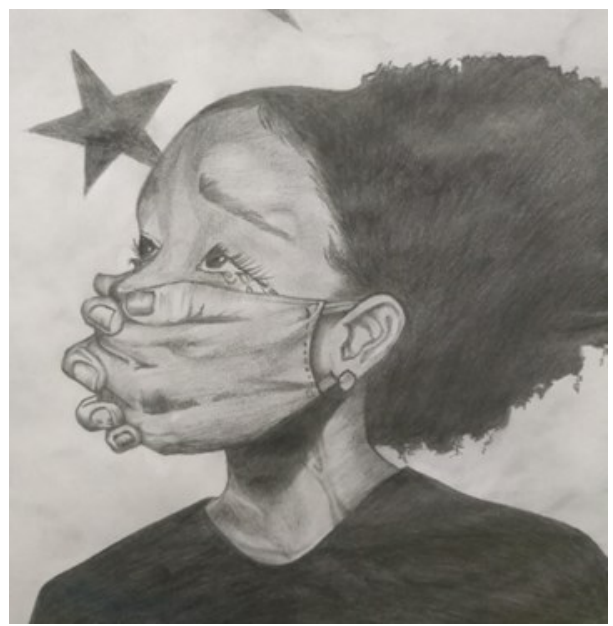

Plate 20: John Baraka (2020)

'I Can't Breathe'

Pencil - 42 × $29 \mathrm{~cm}$

This very expressive depiction of the mask on the face of the hapless woman shows the ironic effect of masks; ideally, the mask is supposed to offer some protection in the era of COVID-19, but it instead impedes breathing to the level of asphyxiation. This, by extension, alludes to the adverse effects of the pandemic on the lives and livelihoods of people akin to a hand literally holding somebody hostage. But the title itself suggests another interpretation; the infringement of fundamental human rights. The surrealism is in itself a statement inspired by George Floyd's death which in his final moments exclaimed, 'I can't breathe!" Hence the mask becomes symbolic of the force and brutality of the perpetrator. Surrealistic drawings are known to carry multipleinterpretations.

\section{Overview of Surrealism and Student Expression}

\section{Student Self-Expression}

From the foregoing, it is evident that students are able to engage the fundamental concept of surrealism as envisaged, helping them to find and delve into a different form of self-expression, full of new-found freedom, freshness and novelty. For instance, in Shauri lako or 'your advice' (Plate 8) it would probably be inconceivable that without triggering the mental processes that are embedded in the unconscious mind, the notion of a separated head that 'willingly vacates the body' and 
temporarily 'disassociates' itself from its headless body, would be an artistic possibility. Rational thinking does not culminate in such imagery. It is the audacity of the hidden thought that brings out this new reality and converts it to something that can subsequently elicit meaning in the real world. It implies that in this new reality, there exists the possibility that we do, indeed, candidly address ourselves, through one wise part of the body emanating great wisdom and addressing another part of the same individuality that is either stubborn or wallows in naiveté.

In Myself and I (Plate 2) the thought that one can hold different versions of his faces in his hands and select the one to wear depending on the dictates of circumstance is truly absurd; it can only exist in the realm of the subconscious. But it is, however, testimony to the tendency of human beings, in the real world, to live a pretentious life, struggling to fit in within any circumstance that they imagine fits their perceived personal interests. This may or may not be an indicator of a degree of personality disorder, but since these kinds of imagery emanate from the workings of the brain, it can be said that dreams often tell great tales embedded with elements of truth. In what men see (Plate 14) the drawing is bizarre; legs cannot possibly replace or overwhelm the head, meaning the brain. This can only occur as imagery flowing in one's dreams which are private. However, in the natural world, this bizarre notion may not be completely farfetched after all; it could, indeed, be that men's heads and by extension, brains, are often overwhelmed by the mere physical sight of feminine 'legs' in their midst, meaning the complete and debilitating fascination with women.

\section{Multiple Interpretations}

In reference to their own synopses, it suggestive that students may not have completely internalised the profoundness of their own surrealism; that their work could be subject to multiple interpretations. This is not unusual since dream-like images formulated in the mind are subject to multiple interpretations by the viewers who interpret them in the context of their own circumstantial experiences. In a safe place (Plate 1) the student artist talks of people concealing something about themselves by having their eyes hidden behind sunglasses. The surrealism of his drawing, however, points to a much deeper phenomenon of eyes epitomising the essence of individual character and the concept of trust. As such, when the eyes vacate their place or are shifted, through the sunglasses, from their usual location on the facial structure, it is akin to erasing the character, leaving the person without a definition, without a tangible, recognisable character. When these eyes are relocated to the forehead beneath the sunglasses, those eyes can no longer exude trust.

\section{Technique}

The students effectively exploit the use of pencil to help them articulate their surrealism using contrasts to emphasise and de-emphasise certain aspects of their composition. Many of them used recognisable human or animal forms with the insertion of the aspect of surrealism vividly brought out as it would probably appear in unconscious imagery flowing in the mind. It should be made clear that the students did not, of course, use the extreme method of waking themselves up using a bell in order to capture the imagery like in the unique approach of Salvador Dali. However, it can be observed that they used some form of visual dream transcription to enable the viewer to glimpse into what was transpiring in their minds.

\section{CONCLUSION}

\section{New Meaning through Surrealism}

Surrealism is not static; in its freshness and provocative thought process, it elicits new meaning through exploration and interpretation of dreams. It can be concluded that the work featured in this paper shows that contrary to how surrealism has often been labelled, as an enigmatic artistic genre that often bears no particular meaning and harbours unusual and bizarre imageries, it does not exist or present itself in an artistic vacuum. The drawings show the emergence of an underlying new meaning in these dream-like imageries that has a degree of impact in the real world. In this regard, there appears to be a relationship between surrealistic thought processes and normal naturalistic thinking, meaning that when one interprets dream-like imageries, there is bound to be a modicum of reference in the natural world. This is not unusual since surrealism bears 
some form of confluence between reality and dreams which according to Breton, culminates in a 'surreality'. This then makes surrealistic work meaningful and profound and also implies that human beings bear vaguely related dream experiences.

Anderson (2019) observes that "a key characteristic of Surrealism is that the artist relies on their unconscious, but reality and the conscious combines with this state of consciousness when the unconscious finds a way to express the reality and render it into the canvases that these artists make." For example, in Pretense (Plate 5), the drawing shows the imagery of a human figure contorted to resemble an ostrich, ostensibly in its quest to deceive its way into acceptability by the real ostrich. If the possibility of such an occurrence appears only in dream-like imageries, the new meaning elicited implies that we all have the tendency to want to be deceitful, fake ostriches to attain our aspirations; meaning harbouring a deceitful character. It implies, then, that we often deceitfully try to gain undeserved acceptability into a given segment of society. Subsequently, this unusual imagery translates into a familiar human phenomenon. Anderson (2019) further notes that "Some artists may use dreams and fantasy to make an expression of the reality, and this can create a dream-like drawing that has meaning, whilst others depend on simply where their subconscious brings them, just like in automatism."

\section{Impact of Surrealism upon Student Self- Expression}

It can be concluded that the experience of exploring surrealism has an impact on the emanation of thought among the students, which aids their selfexpression. When their minds are directed towards the possibility of an alternative source of imagery, in this case, the exploration of their dreams, the possibilities seem endless and exciting. Their minds become accustomed to the surrealist mode of perception. They seem to enter and thrive in a new form of expressive freedom where they are no longer necessarily held accountable for every aspect of their visual rendition. Indeed, they no longer feel that they have to conform to any tenets of artistic composition and that the burden of interpretation falls upon the viewers of their work.
It can be further concluded, therefore, that surrealism offers a welcome break from all other disciplines of art that students have to contend with where they are always guided on how to conduct their creativity, how to construct their work, how to stick to certain prescribed principles, how to organise their thought processes and even what is and what is not the appropriate subject matter. Students are always made aware that there is a certain specificity in all disciplines of art. In the case of surrealism, nobody demands that they must rationalise their thoughts and give a reason for every aspect of their work.

\section{Surrealism and the Generation of Analogy}

It can be concluded that in some of its imageries, surrealism features aspects of analogy. Analogies appear in dreams not deliberately as analogies, as would be composed in regular art, but when dreams are interpreted, then their analogical value is revealed. In Pretense (Plate 5) the ostrich form and that of a human form pretending to be an ostrich are both analogical. There exists no logical reason in the natural world why a human being would wish to convert to an ostrich, but dream-like imageries do no respect such boundaries of logic. When the dream imagery is interpreted, however, it becomes clear that the 'ostrich' itself is not necessarily the subject of concern but the vehicle for analogy modelled within the dream. This is why the interpretation of dreams is vital in order to decipher implied meaning.

\section{The Difference between Surrealism and Other Forms of Art}

It can be concluded that the kind of surrealism depicted in this paper is testimony to the marked difference in approach and intent between surrealism itself and other forms of art. In their synopses and drawings, the student artists demonstrate a rejuvenated aura in expressing their inner thoughts than they would not otherwise have had the opportunity to if they were dealing with a normal imaginative composition or drawing an outdoor scene in their environment. It implies that surrealism provides them with the opportunity for spontaneity of subject matter rather than considered compositional drawings that emanate from the conscious rational mind. It can be concluded, from 
the foregoing, that they found the freedom in surrealism very fascinating and fulfilling.

\section{The Connection Between Surrealism and Thoughtfulness}

It can be observed that through their engagement with the surrealism in their own work, the student artists became more engaged with their subject matter, trying to decipher its innate meaning and implication in their lives, almost as if they were, themselves, seeing the work for the first time. Although it is often argued that the product of surrealism is more about the viewer than the artist, it can be concluded then that surrealism, in this context, bears the capacity to spur the kind of counter-thoughts that stir intellect among the student artists

\section{REFERENCES}

Anderson, W. (2019). Surrealism: Artists and Characteristics. Accessed on November 14, 2020, from Schoolworkhelper.net, https://schoo lworkhelper.net/surrealism-artists-characteristic s/

Azuka, O. (2020). The untamed tongue. Accessed on November 8, 2020, from Guardian.ng, https:/guardian.ng/sunday-magazine/ibruecumenical-centre/the-untamed-tongue/

Cohen, A. (2019). The Artists Putting a Contemporary Spin on Surrealism. Accessed on November 9, 2020, from Artsy.net, https://www.artsy.net/article/artsy-editorialartists-putting-contemporary-spin-surrealism

Craven, J. (2019). Surrealism: the Amazing Art of Dreams. Accessed on November 11, 2020, from Thoughtco.com, https://www.thoughtco.com/w hat-is-surrealism-183312.

Daigle, K. (2013). Self-expression through Surrealism. Accessed on November 15, 2020, from Prezzi.com, https://prezi.com/o3bd63cp5 wsj/self-expression-through-surrealism/

Hilden, N. (2020). What Is Surrealism and Why Is It Important?. Accessed on November 15, 2020, from Artzine.com, https://artzine.com/articles/w hat-is-surrealism-and-why-is-it-important
Mann, J. (2016). How the Surrealist Movement Shaped the Course of Art History. Accessed November 9, 2020, from Artsy.net, https://www.artsy.net/article/artsy-editorialwhat-is-surrealism

Moffat, C. (2011). The origins of surrealism. Accessed on November 10, 2020, from Artsy.net, http://www.arthistoryarchive.com/art history/surrealism/Origins-of-Surrealism.html

Moore, C. A. (2017). Seriously funny: Metaphor and the Visual Pun. Accessed on November 11, 2020, from Medium.com, https://medium.com/ (a) catherineannemoore/metaphor-the-visualpun-1cd7ec7bd044

Ortolano, S. (2017). Surrealism overview. Accessed on November 15, 2020, from rem.routledge.co $\mathrm{m}$, https://www.rem.routledge.com/articles/over view/surrealism-overview

Rippingham, L. (2019). The ultimate guide to surrealism. Accessed on November 15, 2020, from Theartonlinegallery.com, https://theartonli negallery.com/art-appreciation/the-ultimateguide-to-surrealism/

Tarrab, Y. (2013). A look into the subconscious. dreams reveal innermost thoughts and emotions. Accessed November 16, 2020, from Chscourier.com, https://chscourier.com/opinion s/2013/03/07/a-look-into-the-subconsciousdreams-reveal-innermost-thoughts-andemotions/

Wilson, A. (2018). Introduction to Surrealism: An occultnik art movement. Accessed on November 11, 2020 from Spiralnature.com, https://www.s piralnature.com/culture/surrealism-occultnikart-movement/

Wilson, A. (2019). Surrealism: Biomorphic abstraction and objet trouvé assemblage. Accessed on November 11, 2020, from Spiralnature.com, https://www.spiralnature.com /culture/surrealism-biomorphic-abstractionobjet-trouve-assemblage 